\title{
Assessment of electromagnetic fields around selected electrical secondary transformers and its effect on the attached houses in Kuwait
}

\author{
E. Al-Bassam, A. Elumalai
}

\begin{abstract}
This paper presents a detailed description of the work performed on the assessment of electromagnetic fields (EMF) levels around three electrical secondary transformers (substations) installed in a residential area for one year. The EMF measurements were taken during fall, winter, spring, and summer seasons. In addition, the magnetic field measurements for houses that are attached to the substations were taken during summer in August between 10:30 am and 14:00 pm, using EMDEX II and SNAP meters.

The results have shown that no electric field is generated in the vicinity of the substations (underground lines), which is considered an advantage compared to overhead lines, whereas, the magnetic field levels were detected. The measurements of the magnetic field were directly proportional to the electrical consumption, either daily or seasonally. Moreover, the magnetic field levels inside the attached houses were above the value of $0.4 \mu \mathrm{T}$ due to cable lines, electrical panel, wiring circuits, and electrical appliances.

Public awareness campaign towards energy conservation and energy efficiency is required in order to reduce magnetic field levels and improve the environment. Moreover, precautionary guidelines for exposure limits to magnetic fields have to be set for new installations similar to the some European countries.
\end{abstract}

Keywords - EMF levels, public awareness, guidelines

\section{Introduction}

Exposure to electromagnetic fields (EMF) has been steadily rising because of growing demand for electricity, advancing technologies, and changes in social behavior. The benefits of using electricity in everyday life have become a source of concern for the general public regarding potential health effect [1]. The electric and magnetic fields are generated by the equipment installed inside the substation, the power lines passing over and underground, and the electrical appliances. Sometimes, substations are interconnected in such a way that high magnetic field levels are created in a wide area, affecting many of the neighboring houses, especially those that have a small or no front yard.

The health impact due to exposure to electric, magnetic and electromagnetic fields is still an open debate in science and among the public [2]. The first report that showed an association between exposure to electromagnetic fields and childhood leukemia was published by Werthiemer and Leeper in 1979 [3]. These results motivated several sophisticated research studies to examine the possible carcinogenic effect of electromagnetic fields.

As for low frequency EMF range (0-3000 HZ), the World Health Organization (WHO), U.S. National Institute of Environmental Health Sciences [4], and the International
Agency for Research on Cancer [5] have concluded as overall evaluation that power frequency magnetic fields are classified as 'possibly carcinogenic to humans' group 2B based on pooled analyses of studies, which demonstrated a consistent pattern of a two-fold increase in childhood leukemia associated with an average exposure to residential magnetic field above $0.3 \mu \mathrm{T}$ to $0.4 \mu \mathrm{T}$. In the summary of data reported [6], it was mentioned that there is limited evidence about the carcinogenicity of extremely low frequency magnetic fields in relation to childhood leukemia. Whereas, there is inadequate evidence about carcinogenicity from extremely low frequency magnetic field in relation to other cancers or of extremely low frequency electric fields in humans. Also, there is inadequate evidence on the carcinogenicity of extremely low frequency magnetic fields in experimental animals. The National Radiological Protection Board (NRPB) has mentioned in its documents [7] that, "an association between prolonged exposure to intense power frequency magnetic fields and a small raised risk of childhood leukemia has, however, been found, the scientific reasons for which are presently uncertain. In the light of these findings and the requirement for additional research, the need for further precautionary measures should be considered by government." The International Commission on Non-Ionizing Radiation Protection (ICNIRP) has set a guideline [8] that applies to occupational and general public exposure to static magnetic fields. ICNIRP magnetic flux density limit for public exposure is $100 \mu \mathrm{T}$. Some countries have introduced regulatory limits of magnetic field exposure for new installations [6]. A summary of precautionary guidelines to magnetic fields exposure is shown in Table I.

TABLE I. CHRONIC EXPOSURE LIMITS FOR MAGNETIC FIELDS FROM POWER LINES AND SUBSTATIONS IN SOME COUNTRIES

\begin{tabular}{|c|c|c|c|}
\hline Location & Date & Chronic Exposure Limit & $\begin{array}{c}\text { Exposure Limit } \\
(\mathrm{mG} / \mu \mathrm{T})\end{array}$ \\
\hline Netherlands & 2005 & $\begin{array}{l}\text { Requires distance between } \\
\text { power lines and places where } \\
\text { children spend significant time } \\
\text { to limit average exposure. }\end{array}$ & $\begin{array}{c}4.0 \mathrm{mG} / \\
0.4 \mu \mathrm{T}\end{array}$ \\
\hline Switzerland & 1999 & $\begin{array}{l}\text { Limit on magnetic fields near } \\
\text { homes, apartments, schools, } \\
\text { hospitals, and playgrounds based } \\
\text { on maximum rated current of } \\
\text { power line. }\end{array}$ & $\begin{array}{c}10 \mathrm{mG} / \\
1 \mu \mathrm{T}\end{array}$ \\
\hline Italy & 1999 & $\begin{array}{l}\text { Regulations limiting magnetic } \\
\text { fields near nurseries, schools, } \\
\text { hospitals, homes where people } \\
\text { spend more than four hours per } \\
\text { day. }\end{array}$ & $\begin{array}{c}2.0 \mathrm{mG} / \\
0.2 \mu \mathrm{T}\end{array}$ \\
\hline Australia & 2002 & $\begin{array}{l}\text { Court applied magnetic field } \\
\text { limit to impose conditions on } \\
\text { substation and power lines. }\end{array}$ & $\begin{array}{l}4.0 \mathrm{mG} / \\
0.4 \mu \mathrm{T}\end{array}$ \\
\hline
\end{tabular}




\section{Experimental Setup and Measurements}

Three electrical substations were selected based on their distance from houses by less than 1 meter in Qortuba area in Kuwait. These substations plants sized $12.5 * 7.5 \mathrm{~m}^{2}$ consisting of two secondary transformers in addition to extra unit distribution system (UDS) sized $3.5 * 3.5 \mathrm{~m}^{2}$. The proposed schedule for the study was to measure the EMF around the substations for the four seasons during a one-year period to cover the variance in daily load during fall, winter, spring, and summer seasons. Magnetic flux density was measured while walking around the electrical transformers using the calibrated EMDEXII meter held $1.0 \mathrm{~m}$ above the ground and following the Institute of Electrical and Electronics Engineers (IEEE) standard procedure for the measurement of power frequency $\mathrm{E}$ and $\mathrm{H}$ fields from power lines [9]. Fig. 1 shows the method used for taking the magnetic measurements around the electrical transformer. The electric field levels were measured around the electrical substation using EMDEX II with E-Probe. LINDA (LINear Data Acquisition) wheel was attached to EMDEXII during the measurement process, and EMDEXII was set by programming it through EMCALC software. The EMCALC software package, which is an integral part of EMDEX II, was used, since it has a multitude of data analysis features such as statistical analysis, order statistics, exposure timeintegrals, field vs. time graphs, and field vs. distance when attached to LINDA wheel. The measurement process of the transformers for the magnetic field is for different times of the day covering morning (7:00 to 9:00), noon (13:00 to 14:00), and evening (17:00 to 19:00). Whereas, the electric field measurements were carried out during noon time at spring and summer seasons. Moreover, Magnetic field (MF) levels inside the houses and in the vicinity of substations during summer season between 10:30 am to 14:00 pm using EMDEX II and SNAP meters were measured.

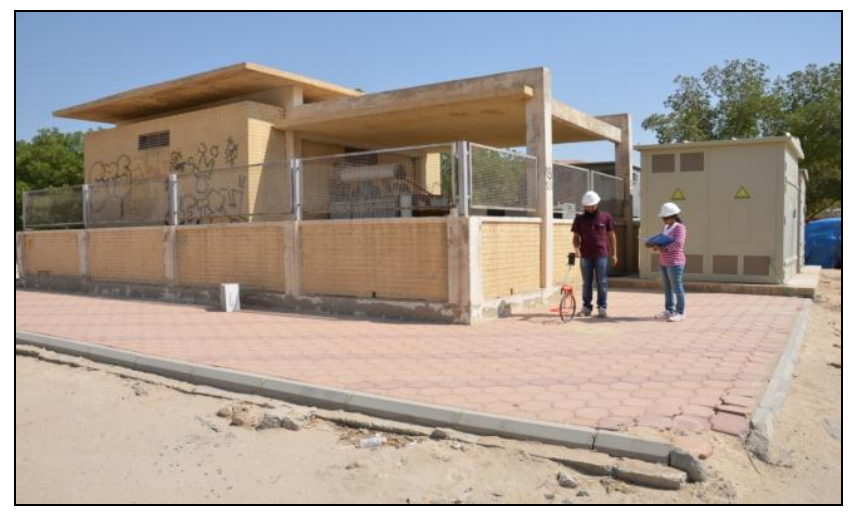

Fig. 1. Measurement taken using LINDA wheel around the electrical transformer.

\section{Evaluation of Electrical and Magnetic Fields Measurements}

Around the electrical transformers there were zero electrical field levels during spring and summer. MF measurements around the selected substations were carried out during the four seasons. The measurements of magnetic levels of fall, winter, spring, and summer are shown in Table II. The table presents the maximum, minimum, and average of the measured magnetic field during each season. The substations' photos are presented in Figs. 2 to 4 and the red arrow indicates the location of the highest magnetic field level. High magnetic field levels were detected for all seasons in front of substation no. 9 because of cable issues.

TABLE II. MAGNETIC FIELD MEASUREMENTS AROUND SUBSTATIONS FOR VARIOUS SEASONS

\begin{tabular}{|c|c|c|c|c|c|c|c|c|c|}
\hline Season & \multicolumn{3}{|c|}{ Substation No. 5 } & \multicolumn{3}{c|}{ Substation No. 9 } & \multicolumn{3}{c|}{ Substation No. 12 } \\
\cline { 2 - 10 } & Max. & Min. & Avg. & Max. & Min. & Avg. & Max. & Min. & Avg. \\
\hline Summer & 2.35 & 0.12 & 1.02 & 4.29 & 0.12 & 0.91 & 3.69 & 0.11 & 0.71 \\
\hline Fall & 1.65 & 0.09 & 0.68 & 2.09 & 0.1 & 0.42 & 0.97 & 0.05 & 0.32 \\
\hline Winter & 0.96 & 0.07 & 0.43 & 1.99 & 0.05 & 0.29 & 0.8 & 0.04 & 0.23 \\
\hline Spring & 1.28 & 0.08 & 0.65 & 2.27 & 0.13 & 0.64 & 1.46 & 0.05 & 0.35 \\
\hline
\end{tabular}

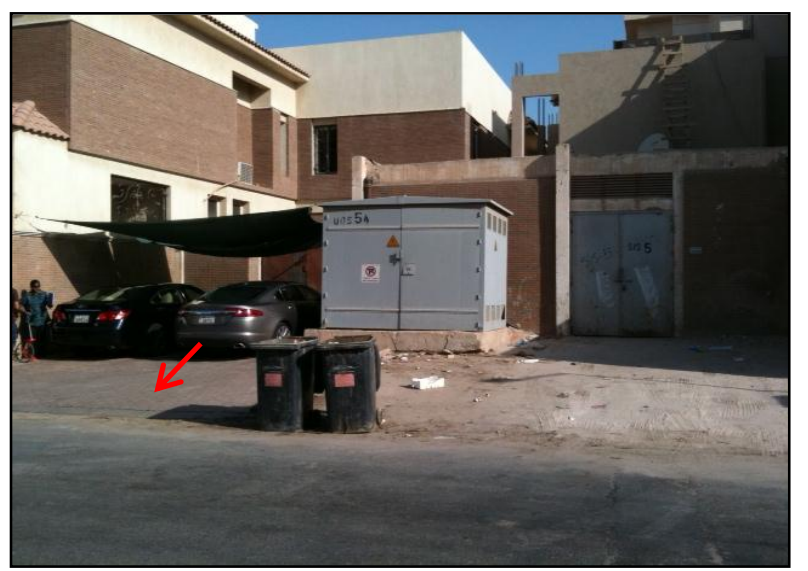

Fig. 2. Qortuba substation no. 5 indicating highest magnetic field levels.

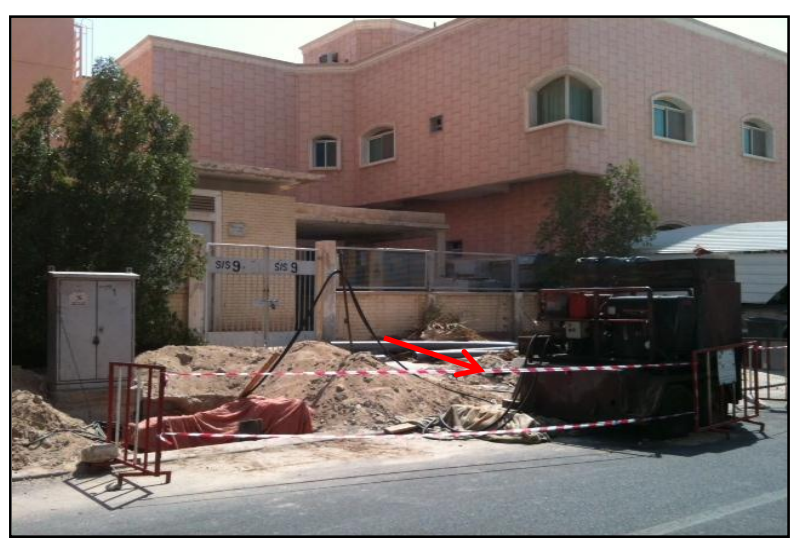

Fig. 3. Qortuba substation no. 9 indicating highest magnetic field levels.

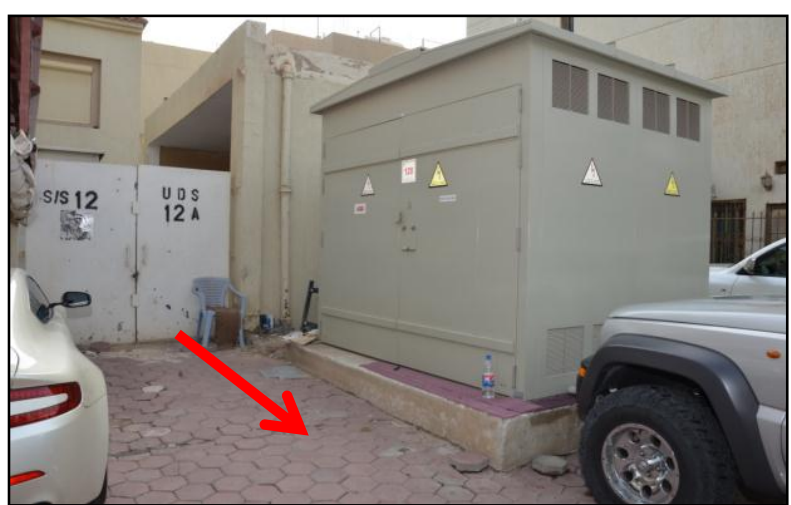

Fig. 4. Qortuba substation no. 12 indicating highest magnetic field levels

Moreover, Figs. 5 to 7 show the magnetic field seasonal profile during morning, noon, and evening for each 
Proc. of the Third Intl. Conf. on Advances in Bio-Informatics and Environmental Engineering - ICABEE 2015 Copyright (C) Institute of Research Engineers and Doctors, USA .All rights reserved. ISBN: 978-1-63248-078-1 doi: 10.15224/ 978-1-63248-078-1-01

substation. The summer profile for all the substations had the highest magnetic field levels, while the winter profile showed the lowest magnetic field levels.

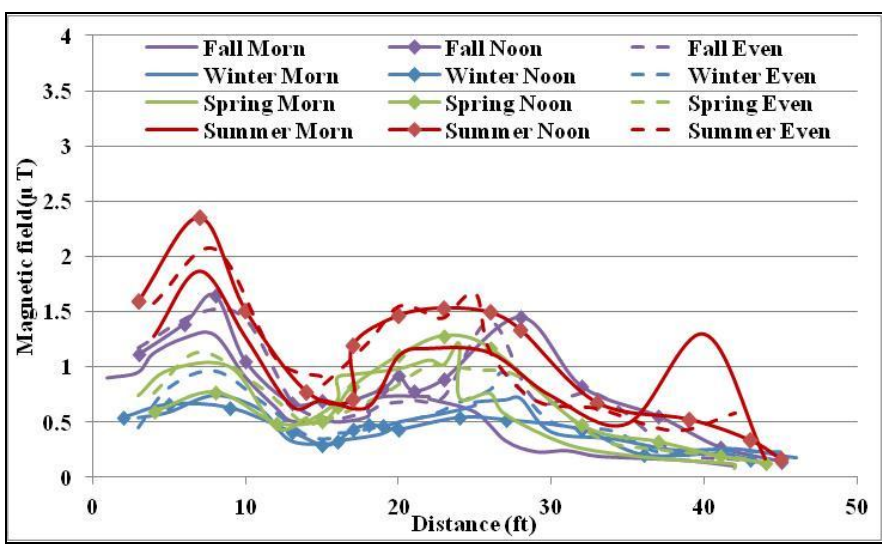

Fig. 5. The magnetic field seasonal profile for substation No. 5 .

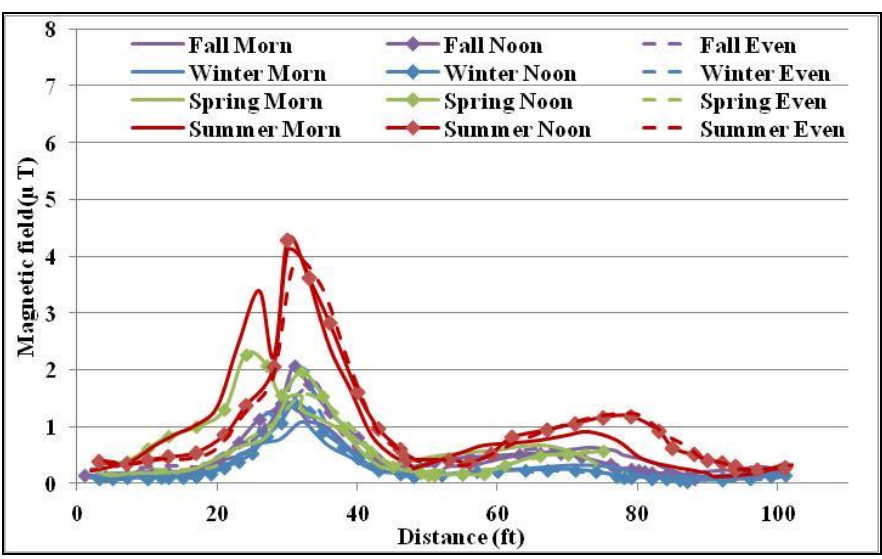

Fig. 6. The magnetic field seasonal profile for substation no. 9 .

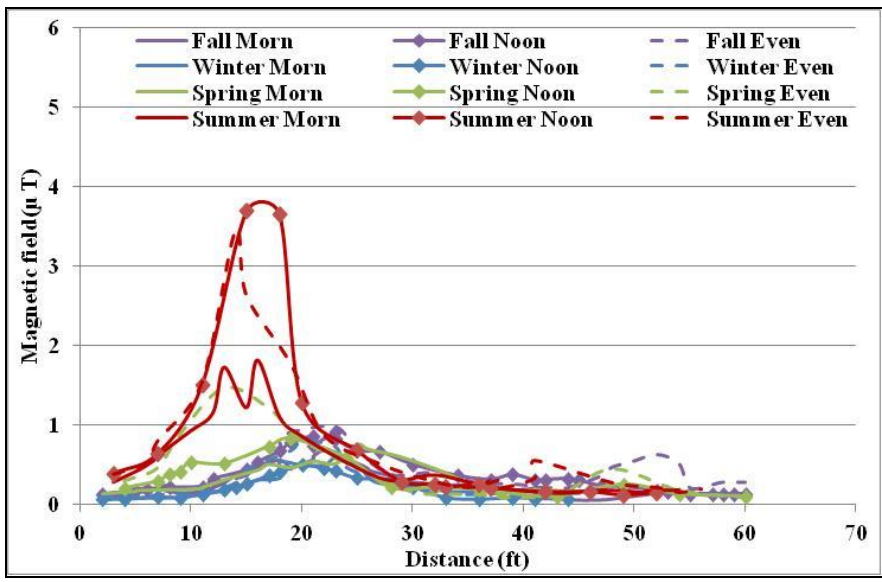

Fig. 7. The magnetic field seasonal profile for substation No.12

The measurements of magnetic field levels for the substations and the attached houses are shown in Table 3. The magnetic field sources in houses fall into two categories: area source which is beyond the immediate area surrounding the source such as power and distribution lines; and local sources where the magnetic field is related to an area within a small distance of the source such as electrical appliances (Farag, 2003). Schematic diagrams to present the magnetic field levels were generated for each substation with its attached houses as shown in Figures 4 to 6 . At substation no. 5 , the attached bedroom in house no. 1 has high levels of magnetic fields. It was recommended to the resident in this room to change the position of his bed and to expose his room to air circulation. For house no. 46 which is attached to substation no. 9, the magnetic field levels were high due to electrical panel and the connected cable from the transformer. While at house no. 3 which is attached to substation no. 12, the highest magnetic levels were detected in the playground area which is adjacent to the transformer wall.

TABLE III. MAGNETIC FIELD FOR SUBSTATIONS AND ATTACHED HOUSES IN QORTUBA AREA.

\begin{tabular}{|c|c|c|c|c|c|}
\hline $\begin{array}{c}\text { Substation } \\
\text { No. }\end{array}$ & $\begin{array}{c}\text { Substation } \\
\text { Maximum } \\
(\boldsymbol{\mu} \mathbf{T})\end{array}$ & $\begin{array}{c}\text { Substation } \\
\text { Average } \\
(\boldsymbol{\mu} \mathbf{T})\end{array}$ & $\begin{array}{c}\text { Attached } \\
\text { House No. }\end{array}$ & $\begin{array}{c}\text { House } \\
\text { Maximum } \\
(\boldsymbol{\mu} \mathbf{T})\end{array}$ & $\begin{array}{c}\text { House } \\
\text { Average } \\
(\boldsymbol{\mu} \mathbf{T})\end{array}$ \\
\hline \multirow{2}{*}{5} & 2.49 & 1.09 & No. 1 & 1.02 & 0.84 \\
\cline { 4 - 6 } & \multirow{2}{*}{6.59} & 1.52 & No. 2 & 0.41 & 0.29 \\
\hline \multirow{2}{*}{12} & 2.05 & 1.06 & No. 44 & 0.25 & 0.18 \\
\cline { 4 - 6 } & & & No. 46 & 1.21 & 0.64 \\
\cline { 4 - 6 } & & & No. 3 & 1.29 & 0.52 \\
\hline
\end{tabular}

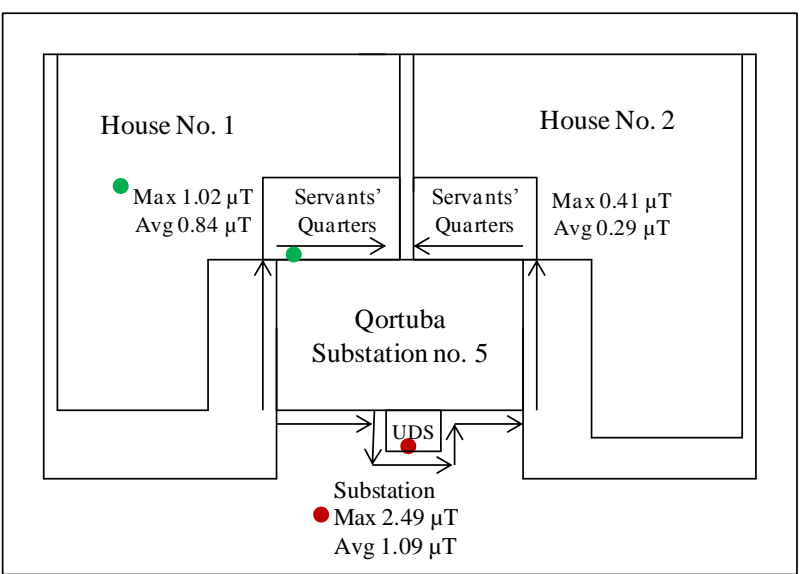

Figure 4. A schematic diagram presenting magnetic field levels in the vicinity of substation No.5

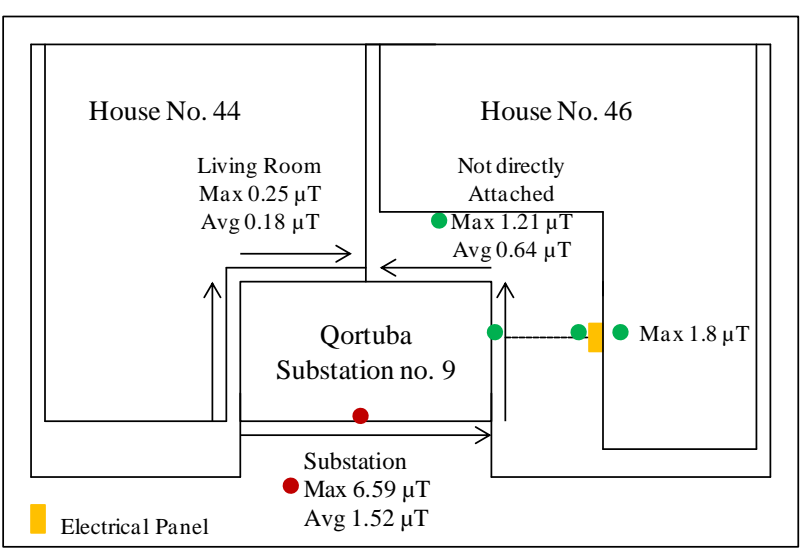

Figure 5. A schematic diagram presenting magnetic field levels in the vicinity of substation No.9 
Proc. of the Third Intl. Conf. on Advances in Bio-Informatics and Environmental Engineering - ICABEE 2015

Copyright (C) Institute of Research Engineers and Doctors, USA .All rights reserved.

ISBN: 978-1-63248-078-1 doi: 10.15224/ 978-1-63248-078-1-01

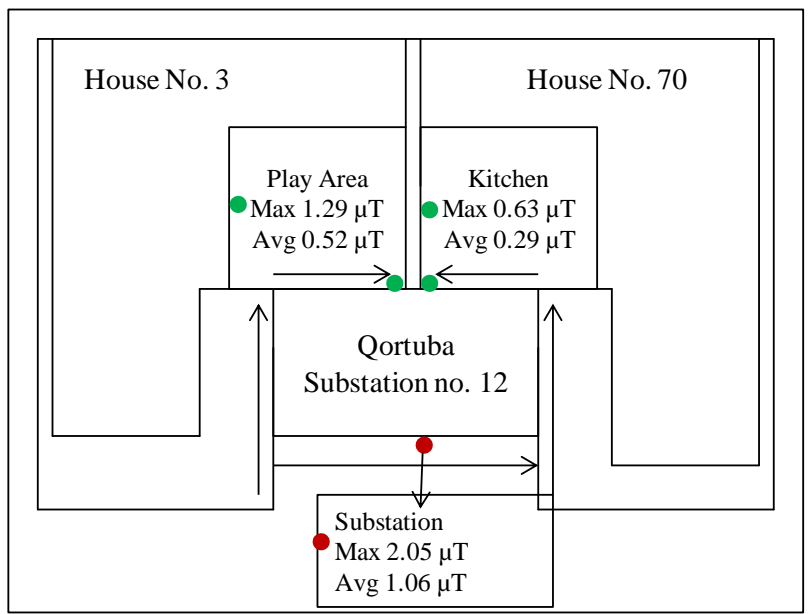

Figure 6. A schematic diagram presenting magnetic field levels in the vicinity of substation No.12

\section{Conclusions and Recommendations}

The magnetic field levels are directly proportional to the electrical load imposed on the transformer. It was noticed that the seasonal profile of the magnetic field is the best example that can highlight this relation. During summer, the electrical load is high because of high demand for cooling throughout hot weather condition.

The measurements show that there are no electric fields in the vicinity of the selected substations which conform to the rule of underground cables having zero electric field since they are screened out by a sheath around the cable. On other hand, the magnetic field levels were recorded and the values vary from one substation to another. These magnetic field levels are governed by the physical parameters of each substation such as power load, cable types and burying depth, layout, age of equipment and maintenance.

It was noticed that the magnetic field levels for most of the houses which are attached to the sides of the electrical secondary transformers were around $0.6 \mu \mathrm{T}$ or less, except for a few positions along the path of cable lines that experienced higher magnetic fields. The maximum magnetic field levels were mostly detected in the front side of the substations. The main cause of having high magnetic field is because of improper burial of cables where they are supposed to be buried in the ground at depth of $75 \mathrm{~cm}$, according to the MEW's technical specifications for low voltage cables.

The magnetic field measurements inside houses which are attached to the secondary transformers were carried out at summer. The recorded measurements showed magnetic field levels with values above $0.5 \mu \mathrm{T}$ due to cable lines, electrical panel, wiring circuits, and electrical appliances. It should be noted that the residents next to substation should be aware of the importance of designing a special layout for their houses based on the location of the substation. It was found that some residents have left a space between the main building and the wall of the substation, and others had utilized this space as storage area to avoid hostile hazard.

\section{Acknowledgment}

The authors would like to thank the Ministry of Electricity and Water in Kuwait for funding this project.

\section{References}

[1] A. Farag, T. Juhana Hashim, H. Hussain, I. Said, and N. Abdul Rahman, "Exposure assessment of electromagnetic fields in Malaysian public schools environment," Proceedings of the International Conference on Non-Ionizing Radiation at UNITEN (ICNIR 2003) Electromagnetic Fields on Our Health $20^{\text {th }}-22^{\text {nd }}$ October 2003, Kuala Lampur.

[2] IARC Working Group on the Evaluation of Carcinogenic Risks to Humans, World Health Organization, and International Agency for Research on Cancer, "Non-ionizing Radiation: Static and extremely low-frequency (ELF) electric and magnetic fields." Vol. No. 80. World Health Organization, 2002.

[3] ICNIRP. Ahlbom, A., et al. "Guidelines for limiting exposure to timevarying electric, magnetic, and electromagnetic fields (up to 300 $\mathrm{GHz}$ ). International Commission on Non-Ionizing Radiation Protection." Health Phys, vol. 74.4, pp. 494-522, 1998.

[4] IEEE 644-1994. 1994. IEEE standard procedure for the measurement of power frequency electric and magnetic fields from AC power lines. Institute of Electrical and Electronics Engineers, CA,USA.

[5] NIEHS/NIH. Electric and Magnetic Fields Associated with the Use of Electric Power. National Institute of Environmental Health Sciences, National Institute of Health, 2002. Sponsored by NIEHS/DOE EMF RAPID Program.

[6] NRPB. Advice on Limiting Exposure to Electromagnetic Fields (0300 Ghz), National Radiological Protection Board, vol. 15, 2004.

[7] M. Otto and K. Ernst, "Electromagnetic fields (EMF): do they play a role in children's environmental health $(\mathrm{CEH})$ ?," Int. J. Hyg. Envir. Heal, vol. 270, pp. 635-644, 2007.

[8] A. S. Safigianni and A. Kostopoulou, "Electric and magnetic field measurements in an indoor electric power substation." J Mater Process Tech, vol. 181, pp. 126-130, 2007.

[9] WHO. World Health Organization, "Extremely Low Frequency Fields. Environmental Health Criteria,” vol. 238, Geneva, 2007.

About Author (s):

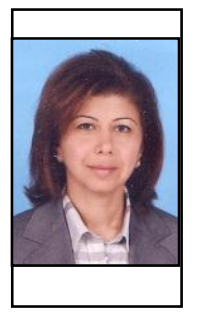

The magnetic field levels were recorded and the values vary from one substation to another. These magnetic field levels are governed by the physical parameters of each substation such as power load, cable types and burying depth, layout, age of equipment and maintenance. 